\title{
Herding and Positive Feedback Trading in American Stock Market: A Two Co-directional Behavior of Investors
}

\author{
Malek Belhoula \\ Department of accounting and finance \\ Ecole supérieure de commerce de Tunis \\ Campus Universitaire de la Manouba, la Manouba 2010, Tunis, Tunisia \\ Kamel Naoui (Corresponding author) \\ Department of accounting and finance, Ecole supérieure de commerce de Tunis \\ Campus Universitaire de la Manouba, la Manouba 2010, Tunis, Tunisia \\ Tel: 216-98-221-922Ｅ-mail: Kamelnaoui@gmail.com
}

Received: February 28, 2011 Accepted: April 2, $2011 \quad$ doi:10.5539/ijbm.v6n9p244

\begin{abstract}
Using aggregate data from DJIA since 1987, this paper attempts to address two potential co-directional behaviors of investors: Herding and positive feedback trading. These behavioral patterns bear interesting implications for market price as they may lead to excess volatility and mispricing. To empirically test for herding behavior, we employ two econometric techniques: the Cross Sectional Standard Deviation (CSSD) and the cross sectional absolute standard deviation (CSAD), while we employ the model formally introduced by Sentana and Wadhwani (1992) to empirically test for positive feedback trading. Our results support the joint significant presence of herding and positive feedback trading behaviors during periods of relatively large market price movements.
\end{abstract}

Keywords: Herding, Feedback trading, Cross sectional Standard Deviation (CSSD), Cross Sectional Absolute Standard Deviation (CSAD), GARCH type model

\section{Introduction}

When agents are heterogeneous in their beliefs, how the market aggregates these beliefs and determines the market equilibrium is an important issue. The agents in real market were unable to process correctly the data. In order to present a simplified picture of actual market activity, scholars assume the interaction between two stylized types of traders: "Smart money" (who buy stocks that are undervalued, and sell the stocks that are overvalued from their fundamental value) versus "Noise traders" (who base their trading activity on noise rather than market information) (De Long, Shleifer, Summers and Waldman, 1990); "Chartists" (who buy stocks based on historical data) versus "Fundamentalists" (who base their trading activity on macroeconomic and other indicators that impact on income flow of security) (Hirsheleifer, 2001); "Informed" versus "Uninformed" (Grossman and Stiglitz (1985), O’Hara, 1995)). Some of these traders have been shown not to react logically to new information. Researches in the field of behavioural finance set of psychological biases underlying the behavioural explanations of the observed security price behaviour (Kahneman and Tverky (1974, 1979), Hirshleifer (2001), Barberis and Thaler (2002), Szyszka (2008)). In fact, individuals are thought to make biased judgments under uncertainty because limited time and cognitive resources lead them to apply heuristics (Hirshleifer (2001)) or showing the same behaviour by either following other groups of investors or trading based on the same signals (Note 1). In such a heterogeneous setting, we would expect traders to normally differ in their trading patterns and exhibit divergence due to their behavioral bias, but two of the most cited patterns of investor behavior, which are positive feedback trading and herding, might show rather a convergence and reveals potential for common ground in their manifestation.

Theoretically, Herding behavior in stock markets has been usually described as a behavioral tendency for an investor to abandon their own information in order to follow the actions of others. Bikhchandani and Sharma (2000) describe herding behavior as the intent by investors to imitate the behavior of other investors. According to Chang, Cheng and Khorana (2000), herding behavior effect on stock price fluctuations can provoke a mispricing of securities given that rational decision making is troubled through the use of biased opinions of expected return and risk. Gleason, Mathur and Peterson (2003) rejected the hypothesis of the presence of herding 
behavior in American stock markets during extreme market fluctuation periods. Cont and Bouchard (2000), suggest that when investors imitate each other, kurtosis excess of stock returns distribution increases.

However, positive feedback trading relates to trading on the basis of historical prices and involves buying stocks when the market is improving and selling stocks when the market is declining. Those followers of this strategy are regarded as positive feedback traders. In line with behavioral explanation, positive feedback trading can be associated with some behavioral bias that affect investor decision such as representativeness heuristic (Tversky and Kahneman (1974), Richard and Thaler (2002), Biais, Hilton, Mazurier and Pouget (2000)), conservatism bias (Hirshleifer (2001)) and overconfidence (Odean(1998)).

Although, much empirical work has been devoted to test for herding and positive feedback trading at micro level, the relationship between the two concepts appears not to have been the fundamental motivation underlying most of those studies. A careful consideration of the theoretical content of these two behavioral patterns reveals potential for common ground in their manifestation. To that end, we aim at addressing this issue by testing for herding and feedback trading on the basis of aggregate data for the Dow Jones stock market in order to see whether these two behavioral patterns exhibited any similarities. Thus, in this respect, the DJIA index is a natural candidate that allows us to capture the behavior of price impact, trend chasing, herding and various other phenomena at the aggregate level.

The remainder of this paper is organized as follows. Section II analyzes the herding pattern and its empirical implications. Section III includes the theoretical background of positive feedback trading, describes the methodology and the empirical findings. Section IV concludes this paper.

\section{Detecting Herd Behavior}

\subsection{Data}

Our sample includes 25 American companies listed on the Dow Jones index. The data set for individual firms contains weekly data of the January 02, 1987 to December 11, 2009 period. Returns are computed by $R_{t}=\log \frac{F_{5}}{F_{r=1}}$. The data is taken from the ECONSTATS data base.

\subsection{Christie and Huang approach}

According to Christie and Huang (1995), Chang, Cheng and Khorana (2000) and Gleason, Mathur and Peterson (2004) and Demirer and Kutan (2006) and Tan, Chiang, Mason and Nelling (2008), the detection of herding behavior during periods of extreme market fluctuations may be achieved using the cross sectional standard deviation indicator. If investors imitate each other, individual returns of stock prices do not deviate significantly from market returns. In the other words, dispersion level decrease during excessive volatility periods. However, when stock returns deviate from market returns, dispersion increases. Christie and Huang (1995) show that if investors during extreme fluctuation periods follow market consensus, dispersion becomes significantly lower than the mean.

The cross sectional standard deviation can be expressed as:

$$
C S S D=\sqrt{\frac{\sum_{i=1}^{N}\left(R_{i}-R_{m, t}\right)}{N-1}}
$$

Where;

CSSD, is the cross sectional standard deviation

$\mathrm{R}_{i}$, is the observed return of a firm $\mathrm{i}$;

$R_{m, t}$ is the cross-sectional average return of the $\mathrm{N}$ returns in the market portfolio

According to Christie and Huang (1995), Chang, Cheng and Khorana (2000), Gleason, Mathur and Peterson (2004) and Henker, Henker and Mitsios (2004), cross sectional standard deviation allows quantifying the degree of dispersion between individual stocks returns and market portfolio returns. Consequently, if investors abandon their own information in order to follow the market consensus (herd behaviour), then we expect a decrease in returns dispersion.

According to Christie and Huang (1995), the herd behaviour test consists in examining whether dispersion degree during extreme fluctuation periods significantly differs from the average dispersions that exclude market returns from extreme distribution tails. More specifically, we need to test the following regression:

$$
\operatorname{CSS} D_{t}=\alpha+\beta_{1} D_{t}+\beta_{2} D_{t}^{2}+\sigma_{0}
$$

Where;

$D_{t}^{U}=1$, if market returns at a date $\mathrm{t}$ lies at the upper tail of the returns distribution 
$D_{t}^{U}=0$, otherwise;

$D_{t}^{L}=1$, if market returns at a date $\mathrm{t}$ lies at the lower tail of the returns distribution

$D_{t}^{L}=0$, otherwise.

The dummies in equation (2) are expected to capture the differences in investors behavior during extreme fluctuation. Thus, statistically significant negative values for $\beta_{1}$ and $\beta_{2}$, would indicate the presence of a herding behavior. However, positive values indicate the absence of a herding behavior (Christie and Huang, 1995).

According to Christie and Huang (1995), in order to define extreme movements tails, we retain the extreme 5\% upper tail and the extreme $5 \%$ lower tail of the distribution of returns.

\section{[Insert Table 1 here]}

Table (1) reports the estimation results of herding behavior using equation (2). The estimations of $\beta_{1}$ and $\beta_{2}$ are all negative and significantly different from zero at $1 \%$ and $10 \%$ levels respectively. The negative values of these dummies indicate that cross sectional standard deviation decreased during price fluctuation periods. According to Christie and Huang (1995), Gleason, Mathur and Peterson (2004) and Henker, Henker and Mitsios (2004), this finding supports the assumption of herding behaviour during extreme fluctuation periods. This decrease is symbolic of the investors' tendency to follow average market behaviour during turmoil periods.

\subsection{Chang, Cheng and Khorana approach}

Chang, Cheng and Khorana (2000) propose a new measure of herding behaviour using the capital asset pricing model. The underling idea of their new indicator of herd is that if investors show an imitating behaviour, then a non-linear relationship between the returns cross-sectional absolute standard deviation and market returns is deduced during extreme market fluctuation periods. According to the conditional CAPM, the absolute value of deviation (AVD) of the returns of a stock $i$ at a date $t$ in relation to market returns is expressed as:

$$
A V D_{i, t}=\left|\beta_{i}-\beta_{m}\right| E_{t}\left|r_{m}-r_{f}\right|
$$

Taking the AVD of all stocks, it is possible to have a proxy of the CSAD, written as E(CSAD).

$$
E\left(C S A D_{t}\right)=\frac{1}{N} \sum_{i=1}^{N}\left|\beta_{i}-\beta_{m}\right| E_{t}\left[r_{m}-r_{f}\right]
$$

Or

$$
\operatorname{CSAD},=\frac{1}{N} \sum_{i=1}^{N}\left|R_{i, t}-\bar{R}_{m, t}\right|
$$

If all investors estimate prices according to the CAPM model, which means the absence of a herding behavior, the $E(C S A D)$ indicator will be positively and linearly correlated with the market returns, $E\left(r_{m, t}\right)$. Deriving the following relationship, in relation to the wished-for market returns, yields:

$$
\begin{gathered}
\frac{\partial E\left(C S A D_{t}\right)}{\partial E_{t}\left(r_{m, t}\right)}=\frac{1}{N} \sum_{i=1}^{N}\left|\beta_{i}-\beta_{m}\right| \succ 0 \\
\frac{\partial^{2} E\left(C S A D_{t}\right)}{\partial E_{t}\left(r_{m, t}\right)^{2}}=0
\end{gathered}
$$

When investors imitate each other, exhibiting herding behavior, the stock returns will not significantly deviate from market returns. Consequently, the returns are not in line with the CAPM model and the relationship between the $E(C S A D)$ indicator and the expected market returns will be non-linearly increasing; it will be rather decreasing. Indeed, Chang, Cheng and Khorana's model (2000), note that rational asset pricing models (CAPM) involve a linear relationship between the deviation between individual asset returns and the return on the market portfolio.

In order to test herding behaviour using Chang, Cheng and Khorana's model (2000), it should to regress the cross-sectional absolute returns on the average return and its square. More specifically, we need to estimate the following specification: 


$$
C S A D_{T}=\alpha+\gamma_{1}\left|R_{m, t}\right|+\gamma_{2} R_{m, t}^{2}+\varepsilon_{t}
$$

During periods of relatively large market price movements, we expect that the increase of CSAD is less than proportional to the extreme values of $\mathrm{R}_{\mathrm{m}, \mathrm{t}}$. The non-linearity between CSAD and market return is estimated by the $\gamma_{2}$ coefficient.

\section{[Insert Table 2 here]}

The results indicate that the $\gamma_{2}$ coefficient is negative and statistically significant. The relationship between CSSD and market return is linear and decreasing. These results indicate the presence of a herding behavior and suggest that the investors tend to suppress their private information in order to follow average market behavior. Under these circumstances the return dispersion tends to increase.

\section{Detecting Positive Feedback Trading Behavior}

In their seminal paper, Delong, Shleifer, Summers and Waldmann (1990a) constructed a noise trader model in order to distinct the different transaction strategies in stock market and show that the presence of noise traders in financial markets can cause prices and risk levels to diverge from expected levels even if all other traders are rational. Noise traders can act as either positive or negative feedback traders who buy (sell) assets when prices rise (fall) or sell (buy) asset when asset prices rise (fall). The issue of feedback trading activity is mainly addressed in Delong, Shleifer, Summers and Waldmann (1990b)'s paper who developed a four phase model to project arbitrage trader who wants to predict noise trading strategy with the positive feedback trader and show that the presence of positive feedback traders can make rational speculation destabilize the security market. If positive feedback traders exist in a market and their trading behavior is expected by rational speculators, the later will not counter the irrational price movement by positive feedback traders. Instead, they will form herd with positive feedback traders. Their behavior will drive price further away from fundamentals and thus increase the volatility of the market.

Assuming that some investors follow a positive feedback trading strategy, Sentana and Wadhwani (1992) investigate the presence of positive feedback trading in the US stock market, using daily data on stock market indexes from 1885 to 1988 . Their results indicate that positive feedback trading strategies induce negative autocorrelation in stock returns during periods of high fluctuations of security prices. In the same spirit, Koutmos (1997) examines the pattern of autocorrelation in several industrialized stock markets (Japan, Italy, UK, Belgium, Australia, and Germany). Koutmos and Saidi (2001) do the same thing in emerging stock markets (Malisia, Singapour, Taiwan, Hong Kong, Thailand and Philippines). Their results support to a large extent the notion of positive feedback trading in developed and emerging stock markets. Bohl and Reitz (2002) show a strong evidence of positive feedback trading in German stock market. Bhol and Siklos (2004) examined the pattern of autocorrelation of stock returns in some mature and emerging markets, the results is consistent with the previous research, were obtained. Toshiaki (2002) examines positive feedback trading in Tokyo stock market, his results indicates that positive feedback trading strategies lead to market volatility.

\subsection{Theoretical background}

According to the theoretical investigations of Sentana and Wadhwani (1992), in a market with rational investors as well as feedback traders, stock returns exhibit autocorrelation of order one, as shown in the equation below:

$$
R_{t}=\alpha+\mu\left(\sigma_{t}^{2}\right)-\gamma \mu\left(\sigma_{t}^{2}\right) R_{t-1}+\varepsilon_{t}
$$

Where,

$R_{t}$ : Stock return at time t.

$R_{5-1}:$ Stock return in the previous period.

$\mu\left(\sigma_{t}^{2}\right)$ : Risk premium modeled as a positive function of the conditional variance of stock price.

The pattern of autocorrelation in returns depends on the type of feedback traders captured by the parameter $\gamma$. Positive feedback trading $\left(\gamma_{>0}\right)$ implies negatively autocorrelated returns and vice versa. The dependence of the pattern of autocorrelation from the type of feedback traders and the extent of volatility becomes obvious, relying on a linear form for $\mu\left(\sigma_{t}^{2}\right)$, the equation (7) can be written as:

$$
R_{t}=\alpha+\mu\left(\sigma_{t}^{2}\right)+\left(\gamma_{0}+\gamma_{1} \sigma_{t}^{2}\right) R_{t-1}+\varepsilon_{t}
$$


At low volatility levels, Sentana and Wadhwani (1992) hypothesize that negative feedback trading dominates, which induces positive serial correlation in return due to the relative strength of $\gamma_{0}$ compared with $\left(\gamma_{1} \sigma_{t}^{2}\right)$. As the risk level increases, the impact of $\left(\gamma_{1} \sigma_{t}^{2}\right)$ compared to $\gamma_{0}$ induces negatively autocorrelated stock returns due to the dominance of positive feedback traders.

\subsection{Data and Empirical findings}

To empirically test for feedback trading, we employ the model formally introduced by Shiller (1984), Sentana and Wadhwani (1992), (equation (8)) in a sample of daily data for the stock price index of the Dow Jones stock market between January 02, 1987 to December 11, 2009.

Returns are computed by $R_{t}=\log \left(\frac{B_{5}}{F_{\mathrm{r}-1}}\right)$. With $P_{t}$ is the index at time t. The data is taken from the ECONSTATS data base. Table (3) reports the summary statistics of the daily returns captured for DJIA.

\section{[Insert Table 3 here]}

The inspection of time series proprieties of market index returns show negative skewness, which implies that the distribution has a long left tail. The Kurtosis is much higher than three, so the distribution is leptokurtic in comparison with normal. Then, the Jarque-Bera test rejects the null hypothesis of normality. This result implies that a GARCH-type model would be appropriate in reflecting such nonlinearities along with asymmetric conditional heteroscedasticity. Thus, in order to test for positive feedback trading we have to specify the measurement equation for conditional variance. Several parametric specifications have been used in the literature for stock returns, the most common being the standard normal distribution. Furthermore, the standardized normality appears to be leptokurtic thereby rendering standard t-student unreliable. Thus, we use two asymmetric GARCH-type models which rely on an explicit volatility measure and allow the conditional variance to respond asymmetrically to positive and negative innovations.

The first asymmetric GARCH model is the exponential GARCH process (Nelson (1991)). Equation (8) will be jointly estimated with the conditional variance specification as follow:

$$
\left\{\begin{array}{l}
R_{t}=\alpha+\mu\left(\sigma_{t}^{2}\right)+\left(\gamma_{0}+\gamma_{1} \sigma_{t}^{2}\right) R_{t-1}+\varepsilon_{t} \\
\ln \left(\sigma_{t}^{2}\right)=\omega+\beta_{0}\left|\frac{\varepsilon_{t-1}}{\sigma_{t-1}}\right|+\beta_{1}\left(\frac{\varepsilon_{t-1}}{\sigma_{t-1}}\right)+\beta_{2} \ln \sigma_{t-1}^{2}
\end{array}\right.
$$

Where $\left|\frac{\varepsilon_{t-1}}{\sigma_{t-1}}\right|$ is the absolute value of the standardized innovations.

This GARCH specification allows for leverage effect. Asymmetry is denoted by statistical significance of $\beta_{1}$, which negative sign implies that volatility increases more when there is bad news.

Another asymmetric GARCH specification is the Threshold GARCH process (TGARCH) (Zakoian (1994)), Equation (8) will be jointly estimated with the conditional variance specification as follow:

$$
\left\{\begin{array}{l}
R_{t}=\alpha+\mu\left(\sigma_{t}^{2}\right)+\left(\gamma_{0}+\gamma_{1} \sigma_{t}^{2}\right) R_{t-1}+\varepsilon_{t} \\
\sigma_{t}=\omega+\beta_{0}\left|\varepsilon_{t-1}\right|+\beta_{1} I_{t-1} \varepsilon_{t-1}+\beta_{2} \sigma_{t-1}
\end{array} \quad \text { Where } I_{t-1}=\left\{\begin{array}{l}
1, \text { si... } \varepsilon_{t-1}<0 \\
0, \text { si... } \varepsilon_{t-1} \geq 0
\end{array}\right.\right.
$$

According to this specification, if $\beta_{1}$ is statistically significant and positive, the influence of good news, $\beta_{0}$ on the conditional variance is lower than the influence of bad news, $\beta_{0}+\beta_{1}$.

\section{[Insert Table 4 here]}

Table (4) reports the estimation results of positive feedback trading model using equation (9) for Dow Jones stock market during 02/01/1987 to 04/12/2009 in daily frequency. Consistent with the theoretical model by Shiller, Sentana and Wadhwani (1992), the $\gamma_{1}$ parameters are significantly negative at $5 \%$ level for each of conditional variance specification. Thus, the results confirm the existence of positive feedback trading strategies in the American stock market which produce negatively autocorrelated returns during periods of high volatility. The GARCH effect coefficient, $\mu$, is insignificant under EGARCH and TGARCH specification which mean that 
rational traders don't essentially influence prices when the volatility changes. Our results are consistent with those of Nelson (1991), Sentana and Wadhwani (1992).

Several explanations are offered to explain why positive feedback traders would be more active during periods of high fluctuation of stock prices. One explanation is that during instances where market volatility is present portfolio sell decisions are dominant. Another is that noise traders engage in intense trading in a stock when the stock prices appreciates because they follow strategies by smart money in believing that the price will weaken in the future. According to Shleifer (2000), many forms of behavior common in financial markets can be described as positive feedback trading, or trend chasing. It can also result from stop-loss orders, which prompt selling in response to price declines (Morris and Shin (2004), Burnnermeier and Pedessen (2003)). Another form of positive feedback trading is the liquidation of the positions of investors unable to meet margin calls (Shleifer, 2000). Positive feedback trading is also exhibited by buyers of portfolio insurance.

\section{Conclusion}

In order to detect herding behavior we used two econometric techniques. The first technique, recommended by Christie and Huang (1995) and Gleason and Lee (2003), uses Cross-Sectional Standard Deviation (CSSD) which measure the dispersion between individual stock returns and the return of market portfolio. The second technique, recommended by Chang, Cheng and Khorana (2000), uses Cross-Sectional Absolute Standard Deviation (CSAD) in order to measure dispersion of returns. Analysing herding behaviour using these two techniques allowed confirming its presence for the investors of the 25 companies listed on the Dow Jones.

Using an explicit measure of conditional variance, our results under both EGARCH and TGARCH methodologies support the hypothesis about presence of positive feedback trading towards the Dow Jones index. In line with the theoretical model of Shiller, Sentana and Wadhwani, the impact of positive feedback trading is to produce negative first order autocorrelation in stock returns during periods of high volatility.

Therefore, herding and feedback trading are the important factors to short term price trend which can destabilize the stock markets by moving prices away from their fundamental values. Thus, the combined significant presence of herding and positive feedback trading in Dow Jones stock market during the same period indicates their conceptual association and similarity in their evolution over time. We contend that the comparative study of the topic across more stock markets would allow us extra insight into the common ground in the relationship between these two behavioural pattern.

\section{References}

Barberis and Thaler. (2003). A survey of behavioral finance, Handbook of the Economics of Finance, G. Constantinides, R. Stulz, M. Harris eds., North Holland, Amsterdam.

Biais, B., Hilton, D., Mazurier, K., and Pouget. (2000). Psychological traits and trading strategies, May 2000, Toulouse University.

Bikhchandani, S., Sharma. (2000). Herd behavior in financial markets: a review. MF Working Paper WP/00/48 (International Monetary Fund, Washington).

Bohl, M., \& Reitz, S. (2002). The Influence of Positive Feedback Trading on Return Autocorrelation: Evidence for the German Stock Market, Working Paper Series of Postgraduate Research Programme.

Bohl, M., \& Siklos, P. (2004). Empirical Evidence on Feedback Trading in Mature and Emerging Stock Markets. Quantitative Finance Research Papers, Sidney.

Boudoukh, J., Richardson, M.P., \& Whitelaw, M.P. (1994). A Tale of Three Schools: Insights on Autocorrelations of Short-Horizon Stock Returns. Review of Financial Studies, 7, pp. 539-573. doi:10.1093/rfs/7.3.539, http://dx.doi.org/10.1093/rfs/7.3.539

Chang, E.C., Cheng, J.W., \& Khorana, A. (2000). An examination of herd behavior in equity markets: an international perspective. Journal of Banking and Finance, 24, pp.1651-1679. doi:10.1016/S0378-4266(99)00096-5, http://dx.doi.org/10.1016/S0378-4266(99)00096-5

Christie, W.G., \& Huang, R.D. (1995). Following the pied piper: do individual returns herd around the market? Financial Analysts Journal, 51, pp. 31-37. doi:10.2469/faj.v51.n4.1918, http://dx.doi.org/10.2469/faj.v51.n4.1918

Cont, R., and Bouchaud, J.P. (2000). Herd Behavior and Aggregate Fluctuations in Financial Markets. Macroeconomic Dynamics, 4, pp. 170-196. doi:10.1017/S1365100500015029, http://dx.doi.org/10.1017/S1365100500015029

DeLong, B.J., Shleifer, A., \& Waldmann, R.J. (1990a). Noise trader risk in finance markets. Journal of Political Economy, 98, pp. 703-38. doi:10.1086/261703, http://dx.doi.org/10.1086/261703

DeLong, B.J., Shleifer, A., \& Waldmann, R.J. (1990b). Positive Feedback Investment Strategies and Destabilizing Rational Speculation. Journal of Finance, 45, pp.379-395. doi:10.2307/2328662, http://dx.doi.org/10.2307/2328662 
Demirer, R., \& Kutan, A.M. (2006). Does herding behavior exist in chinese stock markets?. Journal of International Financial Markets, Institutions and Money 16, pp.123-142. doi:10.1016/j.intfin.2005.01.002, http://dx.doi.org/10.1016/j.intfin.2005.01.002

Engle, R.F. (1982). Autoregressive Conditional Heteroscedasticity with Estimates of the Variance of the United Kingdom Inflation. Econometrica, 50, pp. 987-1007. doi:10.2307/1912773, http://dx.doi.org/10.2307/1912773

Gleason, K.C., Mathur, I., \& Peterson, M.A. (2004). Analysis of intraday herding behavior among the sector ETFs. Journal of Empirical Finance, 11, pp. 681- 694. doi:10.1016/j.jempfin.2003.06.003, http://dx.doi.org/10.1016/j.jempfin.2003.06.003

Grossman S. J., and Stiglitz J. E. (1980). On the Impossibility of Informationally Efficient Markets. American Economic Review, 3, pp. 393-408.

Henker, J., Henker, T., and Mitsios, A. (2006). Do Investors Herd Intraday in Australian Equities?, International Journal of Managerial Finance, 2, pp. 196-219. doi:10.1108/17439130610676475, http://dx.doi.org/10.1108/17439130610676475

Hirshleifer. (2001). Investor psychology and asset pricing. Journal of Finance, 64, pp. 1533-1597.

Koutmos, G. (1997). Feedback Trading and the Autocorrelation Pattern in Stock Returns: Further Empirical Evidence. Journal of International Money and Finance, 16, pp. 625-636. doi:10.1016/S0261-5606(97)00021-1, http://dx.doi.org/10.1016/S0261-5606(97)00021-1

Koutmos, G., \& Saidi, R. (2001). Positive Feedback Trading in Emerging Capital Markets. Applied Financial Economics, 11, pp. 291-297. doi:10.1080/096031001300138690, http://dx.doi.org/10.1080/096031001300138690

Lo, A., \& MacKinlay, A.C. (1990). An Econometric Analysis of Nonsynchronous-Trading. Journal of Econometrics, 45, pp. 181-212. doi:10.1016/0304-4076(90)90098-E, http://dx.doi.org/10.1016/0304-4076(90)90098-E

Morris, Stephen and Hyun Song Shin. (2003). Liquidity Black Holes, Working paper, London School of Economics.

Nelson, D. (1991). Conditional Heteroskedasticity in Stock Returns: A New Approach. Econometrica, 59, pp.347-370. doi:10.2307/2938260, http://dx.doi.org/10.2307/2938260

O'Hara, M. (1995). Market Microstructure Theory. Blackwell Publishers, Oxford, U.K.

Odean, T. (1998). Volume, Volatility, Price and Profit when All Traders are Above Average. The Journal of Finance, Vol LIII, No. 6, 1887-1934. doi:10.1111/0022-1082.00078, http://dx.doi.org/10.1111/0022-1082.00078

Schwert, G.W. (1989). Why does Stock Market Volatility Change over Time?, Journal of Finance, 44, 1115-53. doi:10.2307/2328636, http://dx.doi.org/10.2307/2328636

Sentana, E. (1995). Quadratic ARCH Models. Review of Economic Studies, 62, 639-61. doi:10.2307/2298081, http://dx.doi.org/10.2307/2298081

Sentana, E., \& Wadhwani, S. (1992). Feedback Traders and Stock Return Autocorrelations: Evidence from a Century of Daily Data. Economic Journal, 102, 415-25. doi:10.2307/2234525, http://dx.doi.org/10.2307/2234525

Shiller, R.J. (1984), Stock Prices and Social Dynamics, Brookings Papers on Economic Activity, 2, 457-98. doi:10.2307/2534436, http://dx.doi.org/10.2307/2534436

Shleifer. (2000). Inefficient Market: An introduction to Behavioral Finance. OXFORD University Press.

Szyszka Adam. (2008). From the efficient market Hypothesis to Behavioral Finance: How investors' psychology change the vision of financial market, Working paper Poland University of Economics.

Tan, L., Chiang, T. C., Mason, J. R., and Nelling, E. (2008). Herding behavior in Chinese stock markets: An examination of A and B shares. Pacific-Basin Finance Journal, 16, pp. 61-77. doi:10.1016/j.pacfin.2007.04.004, http://dx.doi.org/10.1016/j.pacfin.2007.04.004

Toshiaki. (2002). Margin requirements, positive feedback trading, and stock return autocorrelations: the case of Japan. Applied Financial Economics, 12, pp. 395-403.

Tversky, A., and D. Kahneman. (1974). Judgment under uncertainty: Heuristics and biases. Science, 185, pp.1124-1131. doi:10.1126/science.185.4157.1124, http://dx.doi.org/10.1126/science.185.4157.1124

Tversky, A., and D. Kahneman. (1979). Prospect theory: An analysis of decisions under risk. Econometrica, 12, pp. 13-32.

Zakoïan, J.-M. (1994). Threshold Heteroskedastic Models. Journal of Economic Dynamics and Control, 18, pp. 931-955.

Note

Note 1. Such as past prices and then, their behavior will be close to positive feedback traders. 
Table 1. Herding Behavior Estimation Results

\begin{tabular}{|l|l|l|l|l|}
\hline \multicolumn{5}{|c|}{$C S S D_{i}=\alpha+\beta_{1} D_{i}^{*}+\beta_{2} D_{i}^{*}+\sigma_{i}$} \\
\hline$a$ & Coefficient & Std. Error & t-Statistic & Prob. \\
\hline Variable & $0.042669^{* * *}$ & 0.001122 & 38.02082 & 0.0000 \\
\hline$F_{1}$ & $-0.013311^{* * *}$ & 0.001698 & -7.839345 & 0.0000 \\
\hline R-squared & $-0.005391^{*}$ & 0.002805 & -1.922133 & 0.0548 \\
\hline Adjusted R-squared & 0.013001 & Mean dependent var & 0.041173 \\
\hline S.E. of regression & 0.011347 & S.D. dependent var & 0.033869 \\
\hline Sum squared resid & 0.033676 & Akaike info criterion & -3.941534 \\
\hline Log likelihood & 1.354118 & Schwarz criterion & -3.928783 \\
\hline F-statistic & 2362.008 & Hannan-Quinn criter. & -3.936730 \\
\hline Prob(F-statistic) & 7.863680 & \multicolumn{2}{|l|}{ Durbin-Watson stat } & 1.642557 \\
\hline
\end{tabular}

$* * *, * *$, and $*$ denote statistical significance at the $1 \%, 5 \%$ and $10 \%$ levels, respectively.

Table 2. Cross-Sectional Absolute Standard Deviation and Herding Behavior

\begin{tabular}{|l|r|r|r|r|}
\hline \multicolumn{5}{|c|}{$C S A D_{T}=\alpha+\gamma_{1}\left|R_{m, t}\right|+\gamma_{2} R_{m, t}^{2}+\varepsilon_{t}$} \\
\hline \multicolumn{1}{|c|}{$\alpha$} & Coefficient & Std. Error & t-Statistic & Prob. \\
\hline$\gamma_{1}$ & 0.476796 & 0.015608 & 30.54891 & 0.0000 \\
\hline$\gamma_{2}$ & 12.20602 & 0.826634 & 14.76594 & 0.0000 \\
\hline R-squared & -26.43225 & 8.740384 & -3.024152 & 0.0025 \\
\hline Adjusted R-squared & 0.237184 & Mean dependent var & 0.688292 \\
\hline S.E. of regression & 0.235906 & S.D. dependent var & 0.394034 \\
\hline Sum squared resid & 0.344435 & Akaike info criterion & 0.708680 \\
\hline Log likelihood & 141.6508 & Schwarz criterion & 0.721431 \\
\hline F-statistic & -421.1453 & Hannan-Quinn criter. & 0.713484 \\
\hline Prob(F-statistic) & 185.6264 & Durbin-Watson stat & 1.607425 \\
\hline
\end{tabular}

$* * *, * *$, and $*$ denote statistical significance at the $1 \%, 5 \%$ and $10 \%$ levels, respectively.

Table 3. Descriptive statistics of Dow Jones stock returns

\begin{tabular}{|l|l|l|l|l|l|l|l|}
\hline Mean & Median & maximum & Minimun & Std. dev & Skewness & Kurtosis & J-Bera \\
\hline 0.0014 & 0.0033 & 0.1069 & -0.200 & 0.023 & -1.013 & 10.40 & 2940.516 \\
\hline
\end{tabular}


Table 4. Positive Feedback trading estimation results

\begin{tabular}{|l|c|c|}
\hline \multirow{2}{*}{ Parameters } & \multicolumn{2}{|c|}{ Conditional variance specification } \\
\cline { 2 - 3 } & EGARCH(1,1) & TGARCH(1,1) \\
\hline$\mu$ & 0.001 & -0.001 \\
& $(1.59)$ & $(1.94)^{*}$ \\
\hline \multirow{2}{*}{$\gamma_{0}$} & -0.674 & -0.692 \\
& $(-0.49)$ & $(-0.79)$ \\
\hline \multirow{2}{*}{$\gamma_{1}$} & 0.004 & -0.001 \\
& $(1.12)$ & $(-0.04)$ \\
\hline$\omega$ & $\mathbf{- 3 5 . 9 4}$ & $\mathbf{- 2 3 . 9 3}$ \\
& $\mathbf{( - 2 . 3 8 ) ^ { * * }}$ & $\mathbf{( - 2 . 6 1})^{* *}$ \\
\hline \multirow{2}{*}{$\beta_{0}$} & -0.695 & $3.84 .10^{-5}$ \\
& $(-6.57)^{* * *}$ & $(5.17)^{* * *}$ \\
\hline \multirow{2}{*}{$\beta_{1}$} & 0.199 & 0.021 \\
& $(7.16)^{* * *}$ & $(0.97)$ \\
\hline \multirow{2}{*}{$\beta_{2}$} & -0.168 & 0.254 \\
& $(-9.59)^{* * *}$ & $(8.45)^{* *}$ \\
\hline
\end{tabular}

Sample period: from $01 / 01 / 2001$ to $10 / 10 / 2010$. Parentheses include the $z$-statistic of the estimates. $*=10 \%$ sign. Level, $* *=5 \%$ sign. Level and $* * *=1 \%$ sign. Level 